\title{
AVALIAÇÃO DOS RISCOS DE PREÇOS NO SETOR SUCROENERGÉTICO
}

\section{Daniel Henrique Dario Capitani*}

RESUMO: O risco de preços é um importante elemento nas decisões dos agentes, sendo desejável a produtores e indústrias compreender suas dinâmicas de preços de mercado às magnitudes dos seus riscos, visando determinar otimamente a produção e comercialização. A análise do risco de preços é particularmente interessante no setor sucroenergético, em razão do portfólio de produtos originados da cana-deaçúcar, como o açúcar, etanol hidratado e etanol anidro. Neste sentido, o presente artigo objetiva mensurar, a partir de diferentes abordagens metodológicas, o nível de risco do setor considerando os preços de açúcar VHP e branco, etanol anidro e hidratado, além da própria cana-de-açúcar. O período de análise se dá ao longo de sete anos de safra. As medidas utilizadas para a mensuração do risco são focadas no risco de retornos indesejáveis (downside risk), como os limites parciais inferiores (LPM), valor em risco (VaR) e valor em risco condicional (CVaR). Cada medida considera os benchmarks de custo de produção e preço médio da safra anterior. Além disso, são calculadas medidas de dispersões tradicionais para comparação com as medidas de riscos propostas. Os resultados indicam diferenças entre o risco calculado por cada método. As medidas de dispersão exibem maior risco para 0 açúcar, enquanto as magnitudes do downside risk mostram maiores extremos de retornos negativos para o etanol anidro e cana-de-açúcar. Em geral, tais constatações permitem agregar elementos introdutórios na discussão acerca das decisões do setor para planejamento de produção, estoques e comercialização de seus produtos, sobretudo sob a temática do risco de preços.

PALAVRAS-CHAVE: Cana-de-açúcar; Downside risk; Gestão de risco; Risco de preços.

\section{ASSESSMENT OF PRICE RISKS IN THE SUGAR-ALCOHOL SECTOR}

ABSTRACT: Price risk is an important factor in decision-taking. Producers and industries must understand the dynamics of market prices and their risks so that

Economista, Mestre e Doutor em Economia Aplicada pela ESALQ/USP; Docente na Faculdade de Ciências Aplicadas da Universidade Estadual de Campinas (UNICAMP), Limeira (SP), Brasil.

E-mail: daniel.capitani@fca.unicamp.br 
production and commercialization may be best determined. Analysis of price risks is specifically relevant in the sugar-alcohol sector due to the list of products derived from sugarcane, such as sugar, hydrated ethanol and anhydrate ethanol. Current paper measures risk level from several methodological approaches taking into consideration the prices of VHP and white sugar, anhydrate and hydrated ethanol, and sugarcane during seven harvest years. Risk measurements are focused on downside risk, such as the lower partial limits, value in risk and conditional value risk. Each measure considers the benchmark production costs and mean price of the previous harvest. Traditional dispersions are also calculated to compare with the measurements of proposed risks. Results indicate differences between calculated risks for each method. Dispersion measurements reveal greater risk for sugar, whereas downside risk greatness reveals great extremes in negative returns for anhydrate ethanol and sugarcane. As a rule, the above discusses decisions of the sector for the planning of production, stocks and commercialization of the products, especially with regard to price risks.

KEY WORDS: Sugarcane; Downside risk; Risk management; Price risk.

\section{INTRODUÇÃO}

A partir do início da década de 2000, o setor sucroenergético brasileiro apresentou uma forte expansão em virtude do aumento da demanda por etanol hidratado, sobretudo decorrente da inserção da tecnologia "bi-flex" em sua frota de veículos automotores. Além disso, o apelo econômico e ambiental pela substituição de combustíveis fósseis por biocombustíveis, bem como as perspectivas de um aumento da demanda internacional por energias renováveis, também colaboraram para estimular investimentos em novas plantas industriais, expansão de área cultivada e incremento em pesquisa e tecnologia para a produção do bioetanol da cana-de-açúcar no Brasil.

No entanto, a discussão acerca das externalidades positivas advindas da produção dos biocombustíveis é contraposta, sobretudo na ótica do comércio internacional entre países, com alegações de alguns efeitos negativos, seja no aspecto ambiental, seja nas alterações no uso da terra, maior desmatamento, à queima dos canaviais e aos impactos no uso da água e do solo, como no aspecto 
socioeconômico, como, por exemplo, nas condições de trabalho no campo e sob a hipótese de que a produção de biocombustíveis em larga escala eleva os preços das commodities agroalimentares.

Recentemente, alguns trabalhos têm buscado demonstrar a eficiência técnica e econômica da produção brasileira do etanol de cana-de-açúcar ${ }^{2}$, focando na questão da sustentabilidade a partir dos aspectos ambientais, sociais e econômicos. Porém, especificamente no âmbito econômico do setor, a literatura é restrita a trabalhos que analisaram o custo de produção agrícola, indicadores socioeconômicos e viabilidade econômica de novos projetos. Pouco foco é dado, por exemplo, para a rentabilidade da produção e à análise do risco de preços. Um assunto relevante para as decisões estratégicas do setor, nesta ótica, se dá em relação ao planejamento do mix de produção ideal das usinas. Para a comercialização de seus produtos finais, torna-se relevante uma compreensão sólida dos riscos associados a cada commodity ofertada. Outro ponto relevante de discussão refere-se à gradual redução da participação de fornecedores próprios na produção de cana-de-açúcar, onde também é cabível uma análise detalhada dos riscos para estes agentes.

Neste sentido, visando contribuir complementarmente à literatura e ao problema de definição do mix ótimo de produção das usinas, este trabalho objetiva avaliar o risco de preços na produção de cana-de-açúcar, açúcar e etanol no Brasil, a partir de benchmarks que delimitam um grau aproximado de retorno desejado para seus agentes, os quais fornecedores de cana e usinas produtoras de açúcar e etanol. Para isso, propõe-se mensurar o risco de preços a partir de abordagens metodológicas distintas. Além das medidas de dispersão comuns, como a volatilidade e o coeficiente de variação, propõe-se avaliar os retornos não desejáveis (downside risk), utilizando os métodos do lower partial moments (LPM), value-at-risk (VaR) e conditional value at risk (CVaR).

Desta forma, espera-se que o presente trabalho contribua com uma análise complementar à sustentabilidade econômica deste setor, analisando os retornos e riscos de preços ao longo dos anos-safra, a partir de diferentes abordagens metodológicas. A análise compreensiva de seus resultados pode auxiliar a tomada de decisões estratégicas para este setor, sobretudo referente ao planejamento do mix

\footnotetext{
Mencionando alguns destes trabalhos, tem-se: Cavallet et al. (2011) e Cunha e Leal (2011).
} 
de produção e reorganizar seus agentes para uma melhor gestão de risco de preços de seus produtos finais. Estas ponderações permitirão um melhor conhecimento acerca dos riscos da atividade, bem como estratégias de produção e comercialização do mix de produção. Além disso, permite promover novos subsídios à literatura referente à sustentabilidade econômica e financeira do setor.

\section{FUNDAMENTAÇÃO TEÓRICA}

\subsection{DECISÕES DE PRODUÇÃO E RISCO DE PREÇOS NO SETOR SUCROENERGÉ- TICO}

Decisões a respeito do mix de produção de uma indústria são balizadas por uma série de variáveis inerentes à própria indústria e ao mercado. Em comparação a outros setores agropecuários, o setor sucroenergéticoo lida com a produção de três commodities centrais, como a cana-de-açúcar, insumo principal para produção de outros dois produtos, o açúcar e o etanol (além da energia cogerada pela queima do bagaço ou palha).

A produção de etanol é balizada majoritariamente de acordo com a lógica do mercado brasileiro de combustíveis, possibilitando à usina determinar volumes específicos na produção de etanol anidro e hidratado. Já a produção de açúcar é influenciada tanto pelo mercado doméstico, como internacional, podendo a usina optar por diferentes produtos finais, como, por exemplo, o açúcar VHP ou branco. Além de seus principais produtos, a usina tem a opção de utilizar outras matériasprimas para geração de valor, como o bagaço e a palha, que possibilitam a cogeração de eletricidade ou a produção de etanol celulósico (segunda geração), a depender de sua capacidade tecnológica e decisões estratégicas. Assim, nota-se que as decisões devem ser alinhadas a uma estratégia que vise otimizar os retornos e minimizar os riscos das usinas.

De acordo com Asaftei (2008), o mix de produção será decidido com base nos retornos dos ativos/produtos, o qual será composto por variações nos preços, quantidades, produtividade, insumos, recursos consumidos, eficiência operacional e 
escala de produção. Neste sentido, as decisões de produção no setor sucroenergético são tomadas de acordo com fatores como os estoques de etanol e açúcar, demanda nos mercados doméstico e internacional (este último, sobretudo para o açúcar), preços de mercado de açúcar e etanol, preços da gasolina, preços da eletricidade, custo de produção de cada produto final, necessidade imediata de geração de caixa, entre outros.

Em geral, tais decisões são tomadas no início da safra. De acordo com Burnquist (1999), o mix entre etanol e açúcar tende a não ter alterações bruscas no curto prazo, mas podem ser revertidos no longo prazo. Por exemplo, até o início da década de 1990, dois terços da cana moída no Brasil eram destinados à produção do etanol, enquanto ao final desta década o açúcar respondia por dois terços da produção do setor (BURNQUIST, 1999). Já nas safras mais recentes, a partir da segunda metade da década de 2000, os volumes têm se equilibrado em proporções semelhantes, com metade da cana destinada à produção de açúcar e a outra a etanol (que por sua vez é afetado pelo crescimento da frota flex e pelos mandatos de adição do anidro na gasolina).

Se por um lado a possibilidade de gerar diferentes produtos finais diversifica o portfólio das usinas, reduzindo riscos relativos às incertezas de mercado, por outro a opção pela produção de um produto em detrimento ao outro pode acarretar em rentabilidades diferentes e aumentar o risco de resultados não satisfatórios. Segundo Sosnoski e Ribeiro (2012), as incertezas nos preços dos produtos do setor sucroenergético brasileiro requerem estratégias financeiras e de produção complexas por parte das usinas, as quais devem ter uma política clara referente às decisões acerca do seu mix de produção.

$\mathrm{Na}$ ótica das disposições estratégicas, Geman e Ohana (2008) apontam que situações sobre decisão de produção podem ser associadas tanto a um problema de otimização do portfólio, refletindo o momento ideal para produção e estocagem, quanto a um problema de valoração do portfólio, consistindo na avaliação do valor global e de cada componente da carteira de opções. Essas situações remetem, assim, em dois tipos de risco: o risco de produção, que surge das incertezas da demanda de longo prazo por parte dos consumidores, e o risco de preços, ligado às variações nos preços das commodities. 
Neste sentido, ressalta-se a importância de um melhor entendimento por parte da usina acerca de qual o risco inerente a cada um de seus produtos, além da compreensão do desempenho de seus resultados financeiros. Assim, entendese que a mensuração do risco de preços de seus principais produtos, como etanol anidro, etanol hidratado, açúcar branco e açúcar VHP, possa fornecer um cenário introdutório para uma melhor discussão acerca das decisões estratégicas de produção do setor sucroenergético.

\subsection{A MENSURAÇÃO DO RISCO}

Em razão de características intrínsecas à sua atividade, produtores agrícolas e agroindústrias lidam frequentemente com incertezas sobre os preços, sobretudo devido à natureza de seus negócios, onde há uma defasagem entre as decisões no plantio até o pós-colheita, ou seja, os preços dos produtos finais são desconhecidos no momento em que as tomadas de decisão concernentes ao plantio são realizadas (MOSCHINI; HENNESSY, 2001). Neste ambiente, uma gestão de risco adequada auxilia na tomada de decisões sob incerteza. A magnitude do risco enfrentado por produtores agrícolas é um mecanismo relevante para tomadas de decisões estratégicas e gestão de risco, o que, por sua vez, ressalta a necessidade de sua mensuração.

Tradicionalmente, o risco na agricultura é mensurado através da volatilidade (desvio padrão) de uma série de preços. Assim, a volatilidade de um preço ao longo do tempo refere-se a todos os desvios do preço médio. Contudo, Rachev, Menn e Fabozzi (2005) argumentam que a volatilidade deve ser usada apenas como uma medida de dispersão, e não como uma medida de risco. Primeiramente, o uso do desvio padrão como medida de risco considera como momentos indesejáveis tanto as dispersões dos preços abaixo como acima da média. Além disso, utiliza-se da média como um benchmark, sem ao menos atentar-se no formato das distribuições dos preços e seus extremos. Na literatura financeira é comum a consideração das propriedades da curtose e assimetria da distribuição de probabilidade dos preços e/ou retornos. Segundo Cont (2001), o uso do desvio padrão falha na aferição de caudas pesadas e assimétricas em distribuições de probabilidades (CONT, 2001). 
Neste sentido, a mensuração de risco através da volatilidade não atende a estas questões, uma vez que não pode detectar caudas pesadas e assimetria.

De acordo com Unser (2000), os agentes frequentemente percebem o risco quando não alcançam um patamar esperado. Nesta ótica, autores como Grootveld e Hallerbach (1999) ressaltam a importância dos investidores classificarem o risco de retornos de seus portfólios abaixo de um benchmark limítrofe, uma vez que retornos acima deste ponto são desejáveis e não devem ser inseridos no cálculo do risco. Assim, o risco seria melhor representado pela probabilidade de perdas a partir deste limiar. Seguindo este raciocínio, diversos estudos têm apontado que a mensuração do risco em apenas um lado da distribuição tende a gerar uma análise mais consistente com as percepções individuais dos investidores, sendo mais relevante, neste contexto, se comparado a medidas que incluam os dois lados da distribuição, como, por exemplo, o desvio padrão (CHEN; LEE; SHRESTHA, 2003; LIEN; TSE, 2002).

Para facilitar a mensuração do risco não desejável, medidas de downside risk (ou one-sided) foram desenvolvidas e aprimoradas ao longo das últimas décadas, a partir das proposições originais de Markowitz (1952; 1959) e Roy (1952). Em geral, propõe-se o foco no lado esquerdo da distribuição de probabilidade, uma vez que este lado representa os retornos negativos de um ativo ou portfólio. Uma dessas medidas é o Lower Partial Moments (LPM), originalmente proposto por Bawa (1978) e Fishburn (1977). O LPM considera apenas os desvios abaixo de um limiar definido e que represente as perdas ao não atingir o patamar mínimo desejado pelo investidor. Sua fórmula é apresentada da seguinte maneira:

$$
\operatorname{LPM}_{\alpha}(r ; B)=\int_{-\infty}^{B}(r-B)^{\alpha} d F(r)
$$

em que $\alpha$ representa a ordem do LPM; $r$ a série dos retornos do ativo; $B$ é o benchmark estabelecido pelo investidor; e $F 0$ é a função de distribuição cumulativa.

Diversas medidas de risco são casos especiais de LPM. Para $\alpha=0$, medese a probabilidade de se ter perdas abaixo do benchmark. Quando $\alpha=1$, o LPM 
representa o desvio esperado dos retornos abaixo do benchmark. Para $\alpha=2$, o LPM será similar à variância, porém com desvios computados apenas abaixo do benchmark. Se $\alpha=2$ e o benchmark é a média da distribuição de probabilidade, então o LPM retornará mesmo valor que a semivariância proposta por Markowitz (1952).

Outras ferramentas para mensuração do downside risk foram desenvolvidas, sobretudo com o avanço computacional, com foco nas caudas (extremos) da função de distribuição de probabilidade. Uma destas medidas é o value-at-risk (VaR), utilizado para avaliar a probabilidade e magnitude de perdas extremas, mensurando a perda máxima que um portfólio pode atingir em um horizonte temporal definido e a certa probabilidade. Por exemplo, se um ativo para uma semana tem um VaR de \$100 mi, com 95\% de intervalo de confiança, entende-se que há 95\% de chance do valor deste ativo não cair mais que $\$ 100 \mathrm{mi}$ ao longo da referida semana.

$O$ VaR pode ser expresso em termos dos retornos do portfólio, ao invés de seu valor monetário, tal como enfatizam Liang e Park (2007). Considerando $R_{t+\tau}$ como o retorno entre o período $t$ até $t+\tau$, e $F_{R, t}$ como a função de distribuição cumulativa de $R_{t+\tau}$ condicionada à informação disponível no período $t, \mathrm{e}-F_{R, t}^{-1}(\alpha)$ $-F_{R, t}^{-1}(\alpha)$ como a função inversa de $F_{R, t}$, o VaR de $R$ ao longo do horizonte temporal $\tau$ e a um nível de confiança $1-\alpha$ pode ser formulado tal como:

$$
\operatorname{VaR}_{R}(\alpha ; \tau)=-F_{R, t}^{-1}(\alpha)
$$

Em geral, a simulação com distribuição de retornos históricos é utilizada para calcular o VaR, embora mecanismos utilizando-se de distribuições semiparamétricas venham sendo aprimoradas e calculadas em trabalhos recentes. No entanto, apesar de suas vantagens, o VaR não permite estimar a magnitude de possíveis perdas além do intervalo de confiança definido. Uma evolução ao VaR para mensuração da área que transcende às perdas estimadas pelo VaR é o conditional value-at-risk (CVaR), ou expected shortfall (ES).

O CVaR mede a perda esperada condicionada ao fato de que o limiar definido no VaR é alcançado, ou seja, mensura a perda esperada no extremo do lado esquerdo da distribuição de probabilidade, dado um intervalo de confiança 
(LIANG; PARK, 2007). Desta forma, esta ferramenta pode ser entendida como um complemento à estimativa do VaR, calculando apenas as perdas em situações de risco extremas além do próprio VaR. No exemplo anterior, discutiu-se que havia 5\% de chance das perdas serem maiores que $\$ 100 \mathrm{mi}$ em um portfólio, ao longo de uma semana. O CVaR permite quantificar qual o patamar máximo que esta perda pode atingir além dos $\$ 100 \mathrm{mi}$. Assim, se o CVaR de uma semana for $\$ 120 \mathrm{mi}$, com 95\% de intervalo de confiança, significa que há 5\% de chances da perda do portfólio ser de até \$120 mi. Como o CVaR é a média das perdas maiores ou iguais ao VaR, pode-se expressá-lo em termos do retorno do portfólio, ao invés da quantia monetária. Assim, sua fórmula é representada da seguinte maneira:

$$
\operatorname{CVaR}(\alpha, \tau)=-E t\left[R_{t+\tau} \mid R_{t+\tau} \leq-\operatorname{VaRt}(\alpha, \tau)\right]=-\frac{\int_{v=-\infty}^{-\operatorname{VaR} t(\alpha, t)} v f_{R, t}(v) d v}{F_{R, t}[-\operatorname{VaRt}(\alpha, \tau)]}=-\frac{\int_{v=-\infty}^{-\operatorname{VaRt}(\alpha, t)} v f_{R, t}(v) d v}{\alpha}
$$

em que $R_{t+\tau}$ denota o retorno do portfólio entre o período $t$ e $t+\tau ; f_{R, t}$ a função de distribuição de probabilidade condicional (pdf) de $R_{t+\tau} ;$ e $F_{R, t}$ a função de probabilidade cumulativa condicional (cdf) do $R_{t+\tau}$ condicional às observações do período $t$.

Tanto o VaR como o CVaR são funções do intervalo de confiança e das distribuições de probabilidade dos retornos. Assim, mesmo portfólios com pequenos desvios padrão podem apresentar elevado VaR e CVaR, dependendo da assimetria e curtose dos retornos e do intervalo de confiança (HARRIS; SHEN, 2006). Ainda, de acordo com Artzner et al. (1999), Dowd (2005) e Liang e Park (2007), enquanto o VaR não atende a algumas propriedades matemáticas, como a ausência de convexidade, monotonicidade, subaditividade, continuidade e invariância transicional, o CVaR atende às referidas propriedades.

\subsection{MÉTODO CIENTÍFICO}

Os procedimentos técnicos de investigação desta pesquisa partem do chamado método de procedimento, os quais são menos abstratos, constituindo-se em etapas de investigação e relacionados a procedimentos técnicos a serem seguidos 
tanto na coleta de dados quanto na análise posterior (PRODANOV; FREITAS, 2013). Segundo Gil (2010), estes métodos têm por objetivo proporcionar ao investigador os meios específicos, visando garantir a objetividade e precisão no estudo dos fatos sociais, sobretudo em respeito à obtenção, ao processamento e à validação dos dados pertinentes à problemática em foco da investigação proposta.

Especificamente, três métodos de procedimentos são adotados: o método observacional, que permite observar fatos recorrentes ou passados (GIL, 2010); o método comparativo, que segundo Prodanov e Freitas (2013) permite analisar o dado concreto, deduzindo elementos constantes, abstratos ou gerais neles presentes; e o método estatístico, que se fundamenta na aplicação da teoria estatística da probabilidade, auxiliando a investigação dos aspectos sociais ou econômicos e caracterizando-se por razoável grau de precisão, validando a análise de questões de ordem quantitativa (GIL, 2010).

Neste sentido, como método observacional, o artigo agrega informações inerentes ao setor, a partir das constatações da literatura empírica que se propôs a avaliar as estratégias relativas ao mix de produção. O método comparativo parte da observação dos retornos dos preços em relação aos dois benchmarks considerados, bem como nas comparações do risco de preços em cada um dos produtos comercializados. Já o método estatístico constitui-se nos cálculos das medidas de risco propostas e nas inferências acerca da estatística descritiva dos dados.

\subsection{DADOS}

Para este trabalho, as medidas de risco são aplicadas considerando os preços mensais da cana-de-açúcar (Consecana), açúcar VHP, açúcar branco, etanol anidro e etanol hidratado. Complementarmente, de forma a expandir o número de observações da análise, também são considerados preços semanais de etanol anidro, etanol hidratado e açúcar cristal (Cepea/Esalq) ${ }^{3}$. O período considerado na análise

\footnotetext{
O uso de duas periodicidades distintas se dá em razão do fato de permitir testar as séries de retornos com uma periodicidade maior, identificando se seus resultados convergem aos resultados das bases com menos observações. A razão de não se ter assumido somente o cálculo com as bases semanais se dá pelo fato de não existir tal periodicidade para os preços da cana-de-açúcar. Além disso, dentre os preços de açúcar, somente o cristal tem base semanal. Neste caso, a base mensal também é importante para avaliar as magnitudes do risco em dois subprodutos desta mesma commodity, no caso, o açúcar branco e o VHP.
} 
inclui seis anos-safra, entre 2007/08 a 2012/13. A mensuração do risco de preços a estes agentes tomou dois benchmarks como referências. O primeiro benchmark refere-se aos custos agrícolas operacionais para a cana-de-açúcar, e industrial para o etanol e açúcar, a partir de dados obtidos junto ao Pecege/Esalq. Outro benchmark a considerar são os preços médios recebidos na safra anterior, considerando as mesmas séries de preços analisadas com defasagem de um ano.

\section{RESULTADOS E DISCUSSÃO}

Primeiramente, como forma de conceituar a discussão a respeito das séries de dados analisadas, na Figura 1 ilustram-se todas as séries de todos os preços utilizados e os benchmarks de custo de produção e preço médio da safra anterior. Observando-se os dados mensais apresentados, constata-se que dentre os produtos ofertados pelas usinas, o etanol, sobretudo o hidratado apresenta maior frequência de retornos negativos em relação ao custo de produção. Nota-se, também, que os fornecedores aparentemente situam-se constantemente com retornos negativos, ressaltando a vulnerabilidade destes agentes em recuperar o capital investido, porém, sugerindo que as usinas que transacionam cana de terceiros podem despender menores quantias para aquisição da matéria-prima e reduzir seus custos totais. Da mesma maneira, observando-se as séries semanais, também na Figura 1, observase que o etanol apresenta maior frequência de períodos de retornos negativos se comparados ao açúcar. 

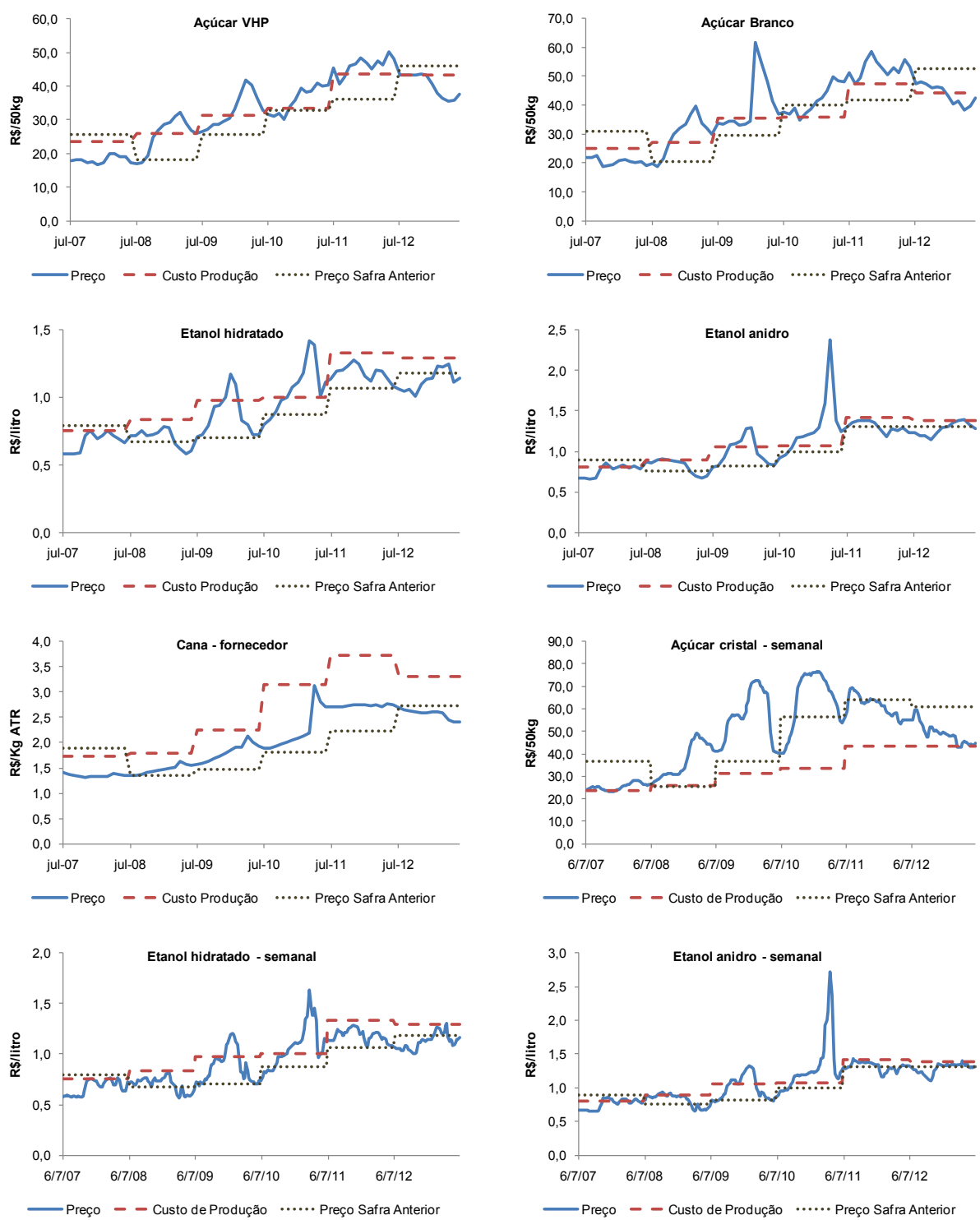

Figura 1. Preços à vista, custos de produção e preços médios das safras anteriores das commodities selecionadas, entre safras 2007/08 a 2012/13

Fonte: Dados da pesquisa.

Aprofundando-se na discussão referente aos dados utilizados, apresenta-se a seguir a estatística descritiva de todos os preços dos produtos em análise, tanto 
mensal como semanal (Tabela 1). Todos os preços, à exceção do etanol anidro, apresentam excesso de curtose negativo, indicando a presença de distribuições com caudas curtas. Já o etanol anidro apresenta excesso de curtose positivo, o que indica a presença de distribuições com caudas pesadas. $\mathrm{O}$ etanol anidro também apresenta assimetria positiva, indicando uma concentração maior dos menores valores, o que pode fornecer indícios, associados à curtose positiva, que há maior probabilidade de preços menores de etanol anidro ao longo do período considerado.

Tabela 1. Estatística descritiva dos preços mensais e semanais, 2007/08 a 2012/13

\begin{tabular}{|c|c|c|c|c|c|c|c|}
\hline & Média & $\begin{array}{c}\mathbf{1}^{\mathbf{0}} \\
\text { quartil }\end{array}$ & $\begin{array}{c}3^{\mathbf{0}} \\
\text { quartil }\end{array}$ & $\operatorname{Max}$ & Min & Assimetria & Curtose \\
\hline Açúcar VHPa & 33,41 & 26,85 & 40,79 & 50,08 & 16,67 & $-0,30$ & $-1,02$ \\
\hline Açúcar Branco ${ }^{a}$ & 38,27 & 31,94 & 47,44 & 61,51 & 18,65 & $-0,21$ & $-0,87$ \\
\hline Etanol Hidratado & 0,95 & 0,72 & 1,14 & 1,42 & 0,58 & $-0,03$ & $-1,32$ \\
\hline Etanol Anidro ${ }^{a}$ & 1,09 & 0,84 & 1,29 & 2,38 & 0,66 & 1,02 & 3,76 \\
\hline Cana-de-açúcar ${ }^{a}$ & 2,05 & 1,48 & 2,61 & 3,13 & 1,32 & 0,07 & $-1,53$ \\
\hline Açúcar Cristal ${ }^{\mathrm{b}}$ & 48,78 & 32,82 & 61,47 & 76,64 & 23,11 & $-0,07$ & $-1,08$ \\
\hline Etanol Hidratado ${ }^{\mathrm{b}}$ & 0,94 & 0,73 & 1,14 & 1,63 & 0,57 & 0,13 & $-1,11$ \\
\hline Etanol Anidro ${ }^{b}$ & 1,08 & 0,84 & 1,31 & 2,73 & 0,65 & 1,26 & 4,45 \\
\hline
\end{tabular}

Fonte: Dados da pesquisa.

Nota: ${ }^{a}$ preços mensais; ${ }^{b}$ preços semanais.

A discussão sobre o risco de preços no setor sucroenergético é pautada primeiramente através da apresentação dos resultados das medidas de dispersão, utilizando-se do desvio padrão (volatilidade) e do coeficiente de variação. Os resultados destas medidas para todos os preços, em todo o período, são apresentados na Tabela 2 . 
Tabela 2. Medidas de dispersão para os preços mensais e semanais, 2007/08 a 2012/13

\begin{tabular}{lcc}
\hline & Desvio Padrão & Coeficiente de variação \\
\hline Açúcar VHPa $^{\mathrm{a}}$ & 10,00 & 0,30 \\
Açúcar Branco $^{\mathrm{a}}$ & 11,76 & 0,31 \\
Etanol Hidratado $^{\mathrm{a}}$ & 0,23 & 0,25 \\
Etanol Anidro $^{\mathrm{a}}$ & 0,29 & 0,27 \\
Cana-de-açúcar $^{\mathrm{a}}$ & 0,56 & 0,28 \\
Açúcar Cristal $^{\mathrm{b}}$ & 15,79 & 0,32 \\
Etanol Hidratado $^{\mathrm{b}}$ & 0,23 & 0,25 \\
Etanol Anidro $^{\mathrm{b}}$ & 0,30 & 0,28 \\
\hline
\end{tabular}

Fonte: Dados da pesquisa.

Nota: ${ }^{\mathrm{a}}$ preços mensais; ${ }^{\mathrm{b}}$ preços semanais.

A partir dos cálculos dos desvios padrão é possível constatar uma maior dispersão nos preços de açúcar, sobretudo o açúcar cristal, para a base de preços semanal. No entanto, em razão de todas as séries de preços estarem em suas bases originais (não logarítmica), a volatilidade tende a ser maior para os produtos cuja escala de preços for maior, como é o caso das séries de preços do açúcar. Consequentemente, o uso do coeficiente de variação torna-se uma medida mais indicada, uma vez que mensura os desvios em relação às médias de cada série de preços, permitindo, assim, uma melhor comparação da variabilidade dos preços entre as commodities.

Os valores dos coeficientes de variação mostram resultados similares para todos os produtos, oscilando entre 24,3\% (etanol hidratado) a 30\% (açúcar branco) nas séries de preços mensais, e entre 25\% (etanol hidratado) a 32,4\% (açúcar cristal) na base semanal. Embora de magnitude semelhante, os resultados ainda indicam uma maior dispersão nos preços de açúcar aos preços de etanol, refletindo em parte os resultados obtidos no cálculo da volatilidade.

Conforme salientado anteriormente, medidas de dispersão como o desvio padrão e o coeficiente de variação consideram os desvios abaixo e acima da média da distribuição dos preços. Assim, ao considerá-las como medidas de risco, o cálculo considerará tanto os momentos de retornos não desejáveis, como também momentos 
de alta de preços, onde há oportunidades de margens positivas ao produtor e usina. Neste sentido, é sensato afirmar que medidas de risco de preços devem considerar somente os desvios abaixo da média ou de um benchmark específico. Desta forma, três outras medidas são incluídas para o cálculo do risco: LPM, VaR e CVaR. Em todas, considera-se apenas os desvios abaixo dos dois benchmarks estipulados (à esquerda da cauda de distribuição dos retornos), os quais o custo de produção e os preços médios recebidos no ano-safra anterior.

Na Tabela 3 são apresentados os resultados do cálculo do LPM para todas as séries de retornos dos preços em relação aos dois referidos benchmarks. É possível constatar que o LPM varia de acordo com cada commodity, benchmark e periodicidade da série em análise. Para as séries mensais o açúcar branco e VHP mostram maior dispersão dos retornos abaixo de ambos os benchmarks, enquanto a dispersão para o etanol e cana-de-açúcar é próxima a zero. Para as séries semanais, no entanto, o risco para o açúcar cristal cai para parâmetros similares ao do etanol anidro e hidratado, o que ressalta a importância em analisar cenários com maior amostra de preços. Complementarmente, ainda considerando as séries semanais, o açúcar cristal apresenta um elevado LPM em relação aos preços da safra anterior, acima dos encontrados para o açúcar branco e VHP no mesmo benchmark, mas com periodicidade mensal.

Tabela 3. Resultados do LPM para os preços mensais e semanais, 2007/08 a 2012/13

\begin{tabular}{lcc}
\hline & LPM custo & LPM safra \\
\hline Açúcar VHPa $^{\mathrm{a}}$ & 3,521 & 4,158 \\
Açúcar Branco $^{\mathrm{a}}$ & 2,672 & 5,888 \\
Etanol Hidratado $^{\mathrm{a}}$ & 0,146 & 0,069 \\
Etanol Anidro $^{\mathrm{a}}$ & 0,113 & 0,072 \\
Cana-de-açúcar $^{\mathrm{a}}$ & 0,711 & 0,232 \\
Açúcar Cristal $^{\mathrm{b}}$ & 0,069 & 7,585 \\
Etanol Hidratado $^{\mathrm{b}}$ & 0,148 & 0,070 \\
Etanol Anidro $^{\mathrm{b}}$ & 0,111 & 0,074 \\
\hline
\end{tabular}

Fonte: Dados da pesquisa.

Nota: ${ }^{\mathrm{a}}$ preços mensais; ${ }^{\mathrm{b}}$ preços semanais. 
Apesar de o LPM indicar um baixo risco de preços para a cana-de-açúcar, etanol anidro e hidratado, e uma maior variação indesejável dos preços do açúcar, corroborando com os resultados encontrados no cálculo das medidas de dispersão, se faz necessária a aplicação de medidas alternativas e que foquem na perda possível aos fornecedores de cana e usinas, considerando cada uma das commodities a serem produzidas e balizando-se nos principais benchmarks para suas tomadas de decisões. Nesta ótica, o cálculo do VaR e CVaR é pertinente e facilitador de uma melhor interpretação da magnitude destes riscos ${ }^{4}$.

A Tabela 4 apresenta os resultados para o VaR utilizando um nível de confiança de $95 \%$ e assumindo distribuições gaussianas (normais). Para todas as séries foram aplicados testes de normalidade de Jarque-Bera, o qual permite analisar se as séries apresentam assimetria e curtose que indiquem normalidade. Para todas as séries dos retornos considerados o teste indicou normalidade, o que justifica o uso da distribuição gaussiana no cálculo do VaR e CVaR.

Tabela 4. Resultados dos cálculos do VaR e CVaR em relação ao custo de produção e preço do ano-safra anterior, 2007/08 a 2012/13

\begin{tabular}{lcccc}
\hline & VaR custo & CVaR custo & VaR ano-safra & CVaR ano-safra \\
\hline Açúcar VHPa $^{\mathrm{a}}$ & $-27,30 \%$ & $-31,21 \%$ & $-32,28 \%$ & $-33,65 \%$ \\
Açúcar Branco $^{\mathrm{a}}$ & $-27,18 \%$ & $-35,34 \%$ & $-46,22 \%$ & $-60,47 \%$ \\
Etanol Hidratado $^{\mathrm{a}}$ & $-31,46 \%$ & $-37,09 \%$ & $-25,51 \%$ & $-33,77 \%$ \\
Etanol Anidro $^{\mathrm{a}}$ & $-34,90 \%$ & $-43,22 \%$ & $-31,85 \%$ & $-41,78 \%$ \\
Cana-de-açúcar $^{\mathrm{a}}$ & $-36,73 \%$ & $-38,87 \%$ & $-29,86 \%$ & $-33,65 \%$ \\
Açúcar Cristal $^{\mathrm{b}}$ & $-19,60 \%$ & $-36,15 \%$ & $-51,18 \%$ & $-66,57 \%$ \\
Etanol Hidratado $^{\mathrm{b}}$ & $-32,53 \%$ & $-38,45 \%$ & $-26,53 \%$ & $-35,06 \%$ \\
Etanol Anidro $^{\mathrm{b}}$ & $-36,15 \%$ & $-44,86 \%$ & $-33,26 \%$ & $-43,58 \%$ \\
\hline Fente: Dados $^{2}$ & & &
\end{tabular}

Fonte: Dados da pesquisa.

Nota: ${ }^{\text {p }}$ reços mensais; ${ }^{\mathrm{b}}$ preços semanais.

4 Ressalta-se que como o VaR e o CVaR são calculados como percentagens dos desvios em relação aos benchmarks, da mesma maneira seus valores são apresentados em forma percentual. 
Focando primeiramente nos retornos em relação ao custo de produção, nota-se no cálculo com as séries de preços mensais que o maior VaR é para a cana-deaçúcar, seguido do etanol anidro. Ambos apresentam a maior magnitude de perda provável, com o etanol anidro podendo alcançar um valor até $43,2 \%$ abaixo do seu custo de produção, quando calculado pelo CVaR. Embora a diferença percentual para os demais produtos não seja maior que 30\% (ou 0,12 p.p.), é possível observar, neste cenário, uma situação inversa à obtida pelos cálculos da volatilidade, coeficiente de variação e LPM. No cálculo do VaR e CVaR, a cana-de-açúcar e o etanol, sobretudo $\mathrm{o}$ anidro, apresentam riscos de perdas indesejáveis maiores às do açúcar. A mesma constatação é observada na análise com as bases de preços semanais, com o etanol anidro podendo atingir patamar de até $45 \%$ abaixo do custo de produção.

Para o VaR calculado em relação ao preço médio recebido no ano-safra anterior nas séries mensais, o maior valor observado se dá nos retornos da produção do açúcar branco $(-46,2 \%)$, enquanto o menor risco é para o etanol hidratado $(-25,5 \%)$. Quando calculado o valor em risco condicionado (CVaR), os coeficientes para o açúcar branco podem atingir, com $5 \%$ de probabilidade, patamares até $60,5 \%$ abaixo do preço da safra anterior, seguido pelo etanol anidro, que pode alcançar até $41,8 \%$ dos valores recebidos no período passado.

Das constatações apresentadas acima, tendências similares são observadas nas séries de preços semanais, onde o preço do açúcar cristal apresenta possibilidades de alcançar um valor de até $66,5 \%$ abaixo do seu preço anterior, e o etanol anidro de aproximadamente $43,6 \%$ menos do que o preço recebido com um ano de defasagem. Em geral, pode-se inferir que os resultados para os preços do açúcar em relação a este bencbmark pode ser, em parte, reflexo da maior dispersão nos preços desta commodity no período em análise, tal como calculado através do desvio padrão, coeficiente de variação e LPM. No entanto, chama a atenção os resultados para o etanol anidro, que diferentemente dos observados no LPM, demonstram patamares fortemente negativos em relação ao preço de referência dos anos-safra anteriores, os quais podem ser, em parte, reflexos das incertezas em relação à oferta e demanda, aos estoques de etanol e, ainda, aos mandatos da utilização de anidro na gasolina ao longo das safras. 


\section{CONSIDERAÇÕES FINAIS}

Este estudo propôs explorar o risco de preços dos principais produtos do setor sucroenergético brasileiro através de diferentes abordagens metodológicas. $\mathrm{O}$ foco principal foi dado na comparação de medidas de dispersão e de downside risk, investigando como a avaliação do risco de cada produto pode variar em cada abordagem. Os resultados mostram que ao se adotar uma medida para ambos os lados da distribuição, como o coeficiente de variação, o açúcar demonstra a maior dispersão na série de preços ao longo do período analisado, embora a diferença para as demais commodities seja relativamente pequena.

De maneira semelhante, os resultados da análise a partir das dispersões em apenas um lado da distribuição, utilizando o LPM, indicam um maior risco nos preços do açúcar, com diferenças significativas para o etanol anidro, etanol hidratado e para a cana-de-açúcar. Por outro lado, os cálculos do VaR e CVaR apontam um maior risco para o etanol anidro e cana-de-açúcar, embora, novamente, as magnitudes não sejam significativamente maiores do que para o açúcar (branco, VHP e cristal) e etanol hidratado.

Estas constatações convergem à discussão recente na literatura sobre gestão de risco. De forma geral, pode-se afirmar que não há um único consenso sobre qual definição de risco deve-se adotar. Considerando um contexto amplo de mercado, diferentes agentes (usinas e fornecedores) podem ter maneiras distintas de gerir e mensurar o risco de preços de seus produtos finais. Por exemplo, uma usina pode adotar sua estratégia de portfólio de produção a partir da análise geral da volatilidade histórica dos preços recebidos, enquanto outra usina está mais interessada em balizar seu planejamento a partir do risco que tal produto pode oferecer se comparado a determinados limiares, como seu custo de produção ou mesmo o preço médio recebido em negociações (safras) anteriores. Desta maneira, suas gestões de risco irão variar de acordo com a forma que elas associem e identifiquem seus riscos.

Outro ponto se dá na própria definição de qual benchmark a ser referenciado na gestão do risco de preços, uma vez que, dependendo da meta estabelecida, a mensuração de risco para uma commodity específica pode variar significativamente. Isto pode ser constatado através dos resultados do VaR e CVaR, os quais exibem 
alguma disparidade nos resultados quando se assumem os preços médios da safra anterior como benchmark, em substituição ao custo de produção.

Embora as medidas de dispersão tenham apontado o açúcar como commodity com maior risco de preços, e o VaR para o custo de produção indica que o etanol anidro e a cana-de-açúcar apresentam maiores probabilidades de atingir magnitudes inferiores para este benchmark, não se pode afirmar que exista um produto do setor que apresente um risco de preços significativamente superior aos demais. Do lado do fornecedor, a cana-de-açúcar apresenta uma dispersão de preços mais moderada, e embora possa situar-se em patamares críticos abaixo do seu custo de produção, seu risco não se distingue significativamente dos demais produtos gerados pela usina. Além disso, o risco de preços para o fornecedor pode ser incrementado ou reduzido dependendo da qualidade da cana-de-açúcar entregue à usina e do tipo de acordo estabelecido previamente à safra.

A usina, por sua vez, deve atentar-se às variações no preço do açúcar no mercado internacional de forma a minimizar riscos de oscilações indesejadas nos preços recebidos ou maximizar receitas. Neste caso, a intensificação de fechamento de posições no mercado futuro, além de bedge de câmbio, deve ser considerada, embora careça de um estudo especificamente neste tema. Para o etanol, cabe uma reflexão relativa à gestão de risco de preços atrelada às decisões sobre a produção de etanol hidratado ou anidro, uma vez que o etanol anidro mostrou-se sempre com piores patamares de risco ao hidratado. Por outro lado, é necessário atentar-se aos mandatos domésticos relativos à utilização do etanol anidro na gasolina, uma vez que cria uma demanda mais inelástica a este produto e facilita a previsão de demanda.

Outra questão importante se refere à produção do etanol de $2^{\mathrm{a}}$ geração, ainda incipiente e foco de diversos estudos de viabilidade técnica, que poderá gerar ganhos de escalas e alavancar receitas das usinas, desde que os investimentos em novas tecnologias mostrem-se economicamente viáveis. Com a implantação de plantas capazes de produzir este etanol será possível analisar os novos riscos de preços nas determinações do mix de produção. Analogamente, este embate deve considerar, também, o custo de oportunidade entre etanol de $2^{\mathrm{a}}$ geração e cogeração de energia elétrica a partir do bagaço e palha da cana-de-açúcar. 
Por fim, deve-se ressaltar que este estudo é preliminar e aborda apenas a questão dos riscos de preços do setor, não se aprofundando na discussão relativa às receitas e margens obtidas nas vendas de cada produto, bem como nas estratégias ótimas para produção e comercialização deste portfólio.

Assim, se por um lado as usinas podem tomar decisões acerca do seu mix de produção embasadas no risco que cada produto pode acarretar, por outro devem atentar-se, também, às receitas brutas e, sobretudo, às margens de lucro geradas através da venda de cada commodity ofertada. Além disso, uma gestão eficiente deve considerar a relação entre as receitas geradas, com a demanda e estoques médios de cada produto entre diferentes intervalos de tempo ao longo de um ano-safra. $O$ conhecimento de tais parâmetros, agregados à questão do risco de preços, pode facilitar na delimitação de estratégias ótimas de comercialização de cada produto ao longo do tempo. Neste sentido, o próximo passo desta pesquisa se dá em compreender e delimitar tais estratégias, aprimorando-se a modelagem de gestão de risco e bedging. Desta forma, serão gerados diversos cenários possíveis para diferentes mix de produção, analisando-se as probabilidades de riscos extremos e de maximização de receitas em cada um, ao longo da safra, além de alternativas de bedge nos mercados físico e futuro.

\section{REFERÊNCIAS}

ARTZNER, P.; DELBAEN, F.; EBER, J.-M.; HEATH, D. Coherent measures of risk. Mathematical Finance, Boston, v. 9, n. 3, p. 203-228, jul. 1999.

ASAFTEI, G. The contribution of product mix versus efficiency and technical change in US banking. Journal of Banking \& Finance, Cambridge, v. 32, n. 11, p. 23362345, nov. 2008.

BAWA, V. S. Safety-first, stochastic dominance, and optimal portfolio choice. Journal of Finance and Quantitative Analysis, Washington, v. 13, n. 2, p. 255-271, jun. 1978.

BURNQUIST, H. L. Panorama da safra sucroalcooleira na Região Centro-Sul. Revista Preços Agrícolas, Piracicaba, v. 14, n. 1, p. 7-10, jan. 1999. 
CAPITANI, D. H. D.; MATTOS, F. L. Risk measurement in commodities markets: how much price do agricultural producers face? In: 2012 AAEA ANNUAL MEETING. Anais... 2012, Seattle: AAEA, 2012, 21 p.

CAVALLET, O. et al. Environmental and economic assessment of sugarcane first generation biorefineries in Brazil. Clean Technologies and Environmental Policy, New York, v. 14, p. 399-410, out. 2012.

CENTRO DE ESTUDOS AVANÇADOS EM ECONOMIA APLICADA - CEPEA. Indicadores de preços físicos de açúcar e etanol. Piracicaba, 2013. Disponível em: < http://www.cepea.esalq.usp.br>. Acesso em: 12 nov. 2014.

CHEN, S. S.; LEE, C.; SHRESTHA, K. Futures hedge ratios: a review. The Quarterly Review of Economics and Finance, New York, v. 43, n. 3, p. 433-465, set. 2003.

CONSELHO DOS PRODUTORES DE CANA-DE-AÇÚCAR, AÇÚCAR E ETANOL DO ESTADO DE SÃO PAULO - CONSECANA. Valores do ATR: cana campo. Ribeirão Preto, 2013. Disponível em: <http://www.udop.com.br > . Acesso em: 15 nov. 2014.

CONT, R. Empirical properties of asset returns: stylized facts and statistical issues. Quantitative Finance, Kiel, v. 1, n. 2, p. 223-236, fev. 2001.

CUNHA, M. P.; LEAL, M. R. L. V. In: 19th EUROPEAN BIOMASS CONFERENCE AND EXHIBITION, 2011, Berlin. Anais... Berlin: [S.n.], 2011. 5p.

DOWD, K. Measuring market risk. 2. ed. Sussex: John Wiley \& Sons, 2005.

FISHBURN, P. C. Mean-risk analysis with risk associated with below-target returns. The American Economic Review, Providence, v. 67, n. 2, p. 116-126, jun. 1977.

GEMAN, H.; OHANA, S. Time-consistency in managing a commodity portfolio: a dynamics risk measure approach. Journal of Banking \& Finance, v. 32, n. 10, p. 1991-2005, out. 2008.

GIL, A. C. Métodos e técnicas de pesquisa social. 6. ed. São Paulo: Atlas, 2010. 
GROOTVELD, H.; HALLERBACH, W. Variance vs downside risk: is there really that much difference? European Journal of Operational Research, London, v. 114, n. 2, p. 304-319, 1999.

HARRIS, R. D. F.; SHEN, J. Hedging and value at risk. The Journal of Futures Markets, v. 26, n. 4, p. 369-390, fev. 2006.

JORION, P. Value at risk: the new benchmark for managing financial risk. Boston: McGrawHill, 2001.

LIANG, B.; PARK, H. Risk measures for hedge funds: a cross-sectional approach. European Financial Management, Oxford, v. 13, n. 2, p. 333-370, mar. 2007.

LIEN, D.; TSE, Y. K. Some recent developments in futures hedging. Journal of Economic Surveys, Chicago, v. 16, n. 2, p. 357-396, jul. 2002.

MOSCHINI, G.; HENNESSY, D. A. Uncertainty, risk aversion, and risk management for agricultural products. In: GARDNER, B.; RAUSSER, G. (Ed.) Handbook of agricultural economics. Boston: Elsevier, 2001, p. 87-153.

PRODANOV, C. C.; FREITAS, E. C. Métodos e técnicas de pesquisa e do trabalho acadêmico. 2. ed. Novo Hamburgo: Feevale, 2013.

PROGRAMA DE EDUCAÇÃO CONTINUADA EM ECONOMIA E GESTÃO DO AGRONEGÓCIO - PECEGE. Custo de produção de cana-de-açúcar e etanol no Brasil: relatórios 2007 a 2013. Piracicaba: FEALQ, 2013, 67 p.

RACHEV, S. T.; MENN, C.; FABOZZI, F. J. Fat-tailed and skewed asset returns distributions: implications for risk management, portfolio selection, and option pricing. Hoboken: Wiley, 2005.

SOSNOSKI, A. A. K. B.; RIBEIRO, C. O. Hedging in the ethanol and sugar production: integrating financial and production decisions. Production, v. 22, n. 1, p. 124-131, jan. 2012. 
UNSER, M. Lower partial moments as measures of perceived risk: an experimental study. Journal of Economic Psychology, Chicago, v. 21, n. 3, p. 253-280, set. 2000.

Recebido em: 16 de abril de 2015 Aceito em: 18 de setembro de 2015 